\title{
Dissociation of airway inflammation and hyperresponsiveness by cyclooxygenase inhibition in allergen challenged mice
}

\author{
L. Swedin*, T. Neimert-Andersson\#, J. Hjoberg", S. Jonasson", M. van Hage\#, \\ M. Adner*, A. Ryrfeldt* and S-E. Dahlén*
}

ABSTRACT: The aim of the current study was to define how cyclooxygenase (COX)-activity affects airway hyperresponsiveness (AHR) and inflammation using interventions with COX inhibitors at different time points during allergen challenge and/or prior to measurement of AHR in an eosinophil-driven allergic mouse model. Inflammatory cells were assessed in bronchioalveolar lavage (BAL) and $A H R$ was evaluated as the total lung resistance to methacholine (MCh) challenge.

Administration of FR122047 (COX-1 inhibitor) during ovalbumin (OVA) challenge and prior to MCh challenge enhanced AHR without affecting the inflammatory cell response. In contrast, administration of lumiracoxib (COX-2 inhibitor) during the same time period had no effect on AHR but reduced the inflammatory cells in BAL. Nonselective COX inhibition with diclofenac both enhanced the AHR and reduced the inflammatory cells.

Administration of diclofenac only during OVA challenge reduced the cells in BAL without any changes in AHR, whereas administration of diclofenac only prior to MCh challenge enhanced AHR but did not affect the cells in BAL.

The present study implicates distinct roles of prostanoids generated along the COX-1 and COX-2 pathways and, furthermore, that inflammatory cells in BAL do not change in parallel with AHR. These findings support the fact that AHR and the inflammatory response are distinct and, at least in part, uncoupled events.

KEYWORDS: Airway hyperresponsiveness, allergic mouse model, cyclooxygenase inhibition, eosinophilic allergic reaction, prostaglandins

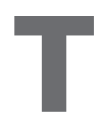
he role of prostaglandins (PGs) and other cyclo-oxygenase (COX) products in asthmatic airway inflammation remains unclear. Despite a presumed pro-inflammatory action of most PGs in airways, studies in murine models of airway inflammation have shown that antigen-induced airway responsiveness in fact may be increased after pharmacological inhibition or gene deletion of COX iso-enzymes [1-4]. There are two isoforms, COX-1 and COX-2, which catalyse the initial step in the formation of PGs and thromboxane (TXA) from arachidonic acid [5]. Therefore, the first objective of the current study was to further define the role of the two isoenzymes by intervention with selective COX-1 and COX-2 inhibitors in a mice model of allergic airway inflammation and airway hyperresponsiveness (AHR) to methacholine (MCh).

The models of airway inflammation generally involve three different phases. First, the animals are sensitised to produce antibodies towards a foreign antigen, most often ovalbumin (OVA). Thereafter, the animals are repeatedly challenged with inhalation of the same antigen to induce airway inflammation. This challenge induces an inflammatory process through an allergic reaction expressed as increased numbers of inflammatory cells in the lungs or bronchoalveolar lavage (BAL) fluid [6]. The last part of the "mouse asthma" protocols involves assessment of the allergen-induced AHR by challenge with a bronchoconstrictor, most often MCh. It is often assumed that the increased inflammatory cell count in BAL is directly related to the appearance of AHR.

From previous studies reporting the effects of COX inhibition on airway inflammation and AHR in mouse models [1-4], it is not known at which time points in the sequence of events from sensitisation, induction of allergic inflammation
AFFILIATIONS

*The National Institute of Environmental Medicine, Division of Physiology, Karolinska Institutet, ${ }^{\#}$ Dept of Medicine Solna, Clinical Immunology and Allergy Unit, Karolinska Institutet and University Hospital, Stockholm, and "Dept of Medical Sciences, Clinical Physiology, Uppsala University, Uppsala, Sweden.

CORRESPONDENCE L. Swedin

The National Institute of Environmental Medicine Division of Physiology Scheeles väg 1 Box 287

Karolinska Institutet SE-171 77 Stockholm Sweden

E-mail: linda.swedin@ki.se

Received:

Feb 282008

Accepted after revision:

Feb 092009

First published online:

Feb 272009 
and measurement of AHR that the COX acts. The secondary aim of the study was therefore to define the time points for effects of COX inhibition in this model by administration of the nonselective COX inhibitor diclofenac using three different strategies. Thus, its effects on AHR and BAL cell responses were compared when diclofenac was administered both during the OVA challenge and prior to the MCh challenge as well as when it was given either during the OVA challenge only, or only prior to the MCh challenge.

The airway responses were assessed by measuring AHR in anaesthetised mice based on the response of total lung resistance to $\mathrm{MCh}$ challenge and airway inflammation was assessed by measurement of inflammatory cells in BAL. To define mechanisms contributing to the changes in AHR and infiltration of cells into the airways, formation of key eicosanoids and cytokines in BAL were also investigated.

\section{MATERIALS AND METHODS}

\section{Animals}

Female BALB/c mice (8-13 weeks of age) were purchased from Charles River (Sulzfeld, Germany). The animals were housed in plastic cages with absorbent bedding material and were maintained on a $12 \mathrm{~h}$ daylight cycle. Food and water were provided ad libitum. All animal experiments were approved by the regional committee of animal experimentation ethics (Stockholm, Sweden).

\section{Sensitisation and airway challenge}

Mice were actively sensitised by i.p. injection of $10 \mu \mathrm{g}$ OVA (grade II; Sigma-Aldrich, St Louis, MO, USA) in $1 \mathrm{mg} \mathrm{Al}(\mathrm{OH})_{3}$ (Sigma-Aldrich) in a total volume of $200 \mu \mathrm{L}$ on days 0 and 7 (fig. 1). Allergic airway inflammation was induced by challenge of 1\% OVA (in PBS), or PBS (controls) aerosols on days 14,15 and 16, delivered with an ultrasonic nebuliser (UltraNeb $b_{\approx}$ DeVilbiss, Somerset, PA, USA) for $30 \mathrm{~min}$. Lung mechanics were assessed $24 \mathrm{~h}$ after the last OVA-challenge.

\section{INTERVENTIONS}

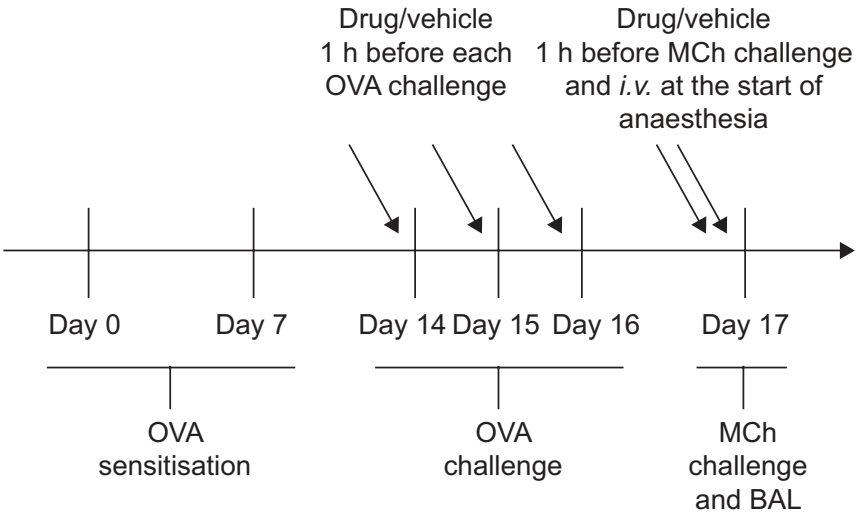

FIGURE 1. Allergic ovalbumin (OVA) mouse model: sensitisation and challenge protocol with the indication of drug administration. Drug interventions were administrated using three different strategies; 1) both during the OVA challenge and prior to methacholine (MCh) challenge; 2) during OVA challenge only; and 3) prior to MCh challenge only. BAL: bronchoalveolar lavage.

\section{Intervention with COX inhibitors}

Diclofenac sodium $\left(1 \mathrm{mg} \cdot \mathrm{kg}^{-1}\right.$ body weight; nonselective COX inhibitor; Cayman Chemicals, Ann Arbor, MI, USA), FR122047 $\left(5 \mathrm{mg} \cdot \mathrm{kg}^{-1}\right.$ body weight; selective COX-1 inhibitor; Cayman Chemicals), lumiracoxib $\left(1 \mathrm{mg} \cdot \mathrm{kg}^{-1}\right.$ body weight; selective COX-2 inhibitor; SynphaBase, Muttenz, Switzerland) or solvent control was administered i.p. $1 \mathrm{~h}$ before each OVA challenge, $1 \mathrm{~h}$ before the MCh challenge and as an i.v. injection at the start of the anaesthesia (fig. 1). Control mice received PBS-challenge instead of OVA aerosol. As a second control, either of the COX inhibitors was given in the same dose to mice sensitised to OVA but PBS-challenged. Since only the median inhibitory concentration (IC50) for diclofenac is described in mouse (IC50 COX-1/COX-2 $0.5 / 0.35 \mu \mathrm{g} \cdot \mathrm{mL}^{-1}$ ) [7] the dose used for FR122047 (IC50 COX-1/COX-2 0.028/65 $\mu \mathrm{g} \cdot \mathrm{mL}^{-1}$ in recombinant human assay) [8] and lumiracoxib (IC50 COX-1/ COX-2 67/0.13 $\mu \mathrm{g} \cdot \mathrm{mL}^{-1}$ in human whole blood assay) [9] were selected from in vitro studies in mice and rats [9] in which they were both effective and selective.

To study the time-point of the effect of COX-inhibition, diclofenac was also administered in the same dose $\left(1 \mathrm{mg} \cdot \mathrm{kg}^{-1}\right.$ body weight) either only during the OVA challenge (intranasal $100 \mu \mathrm{g}$ OVA) or acute prior to the MCh challenge and as an i.v. injection at the start of anaesthesia without administration during the OVA challenge.

\section{Determination of AHR}

Mice were anaesthetised with pentobarbital sodium i.p. (90 $\mathrm{mg} \cdot \mathrm{kg}^{-1}$ body weight; from Apoteket Produktion and Laboratorier AB, Stockholm, Sweden), tracheostomised with a metal 18 -gauge cannula and placed on a $37^{\circ} \mathrm{C}$ heating pad to maintain body temperature during the anaesthesia. Mice were mechanically ventilated in a quasi-sinusoidal fashion [10] with an animal ventilator (FlexiVent $\mathbb{R}$; Scireq, Montreal, QC, Canada) [11] at a frequency of $2.5 \mathrm{~Hz}$ and a tidal volume of $12 \mathrm{~mL} \cdot \mathrm{kg}^{-1}$ body weight. In this mode, the pressure waveform is only sinusoidal during inflation not deflation, mimicking conventional rodent ventilators. Once the ventilation began, bilateral thoracotomies were performed to equalise the pleural pressure to atmospheric pressure and to exclude any chest wall contribution to pulmonary mechanics. The positive endexpiratory pressure was set to $3 \mathrm{cmH}_{2} \mathrm{O}$. To stabilise the baseline respiratory lung resistance $(R \mathrm{~L})$ and ensure similar volume history, four sigh manoeuvres to three times the tidal volume were performed at the beginning of the experiment defined as incremental increase and decrease of lung volume during $16 \mathrm{~s}$. After $5 \mathrm{~min}$ resting, the experiment was started and increasing doses $\left(0.03,0.1,0.3,1\right.$ and $3 \mathrm{mg} \cdot \mathrm{kg}^{-1}$ body weight) of MCh (acetyl- $\beta$-methylcholine chloride; SigmaAldrich) was injected through the tail vein. RL and pulmonary compliance (CL) were measured by assuming a singlecompartment linear model and multiple linear regressions at a sinusoidal frequency of $2.5 \mathrm{~Hz}$ every eight breaths for $3 \mathrm{~min}$ after each injection [12]. Changes in reactivity and sensitivity were assessed using nonlinear regression analysis to calculate the maximum responses $(E \max )$ and effective dose for half maximal response (ED50). Since a dose of $10 \mathrm{mg} \cdot \mathrm{kg}^{-1}$ body weight of $\mathrm{MCh}$ caused such bradycardia that it resulted into cardiac arrest with no further increase in AHR, the Emax was reached at $3 \mathrm{mg} \cdot \mathrm{kg}^{-1}$ or, in some experiments, even earlier 
because of the same phenomenon. $C_{L}$ is expressed as the maximal decrease to each MCh dose.

\section{BAL}

BAL was performed in all controls and treated animals directly after AHR measurements. In short, a total volume of $1 \mathrm{~mL}$ ice cold PBS containing $0.6 \mathrm{mM}$ EDTA was used to lavage the lungs three times. Red blood cells were lysed by resuspending the cells in $100 \mu \mathrm{L}$ lysis buffer $\left(150 \mathrm{mM} \mathrm{NH}_{4} \mathrm{Cl}, 10 \mathrm{mM} \mathrm{KHCO}_{3}\right.$ and $0.1 \mathrm{mM}$ EDTA at $\mathrm{pH} 7.2$ ) for $2 \mathrm{~min}$ at room temperature followed by washing in $1 \mathrm{~mL}$ PBS. The total number of cells was then counted and calculated back to cells $\cdot \mathrm{mL}^{-1}$ BAL. For differential cell counts, a minimum of 300 cells were counted per BAL sample.

\section{Measurements of released eicosanoids}

$\mathrm{PGD}_{2}$ (PGD 2 -MOX; Cayman Chemicals, Ann Arbor, MI, USA), $\mathrm{PGE}_{2}, \mathrm{TXA}_{2}$ and cysteinyl leukotrienes (CysLTs) were measured in BAL fluid using enzyme immuno assay (EIA; Cayman Chemicals). All samples were assayed in duplicate. EIA TXA was measured as the stable metabolite $\mathrm{TXB}_{2}$. CysLT were measured as leukotriene (LT) $\mathrm{E}_{4}$, the end metabolite of $\mathrm{LTC}_{4}$ and $\mathrm{LTD}_{4}$. The assay detection limits for the different mediators were $3.9 \mathrm{pg} \cdot \mathrm{mL}^{-1}$ for $\mathrm{PGD}_{2}$ and $7.8 \mathrm{pg} \cdot \mathrm{mL}^{-1}$ for $\mathrm{PGE}_{2}, \mathrm{TXB}_{2}$ and $\mathrm{LTE}_{4}$. Results below detection limits were set as detection limit in the statistical evaluation.

\section{Measurement of released cytokines}

The concentrations of interleukin (IL)-4, IL-5, IL-10, IL-13, tumour necrosis factor (TNF) and interferon (IFN)- $\gamma$ in BAL fluid were analysed in all control and treated animals measuring fluorescence-labelled beads (Cytometric Bead Array; BD Biosciences, San Diego, CA, USA) by flow cytometry, following the manufacturer's protocol, and compared with known standards. The detection limit was $5 \mathrm{pg} \cdot \mathrm{mL}^{-1}$.

\section{Immunoglobulin $\mathrm{E}$ and immunoglobulin $\mathrm{G}_{1}$ analysis}

Blood was collected by cardiac puncture for measurement of antibody titres using ELISA and plates coated with $5 \mu \mathrm{g} \cdot \mathrm{mL}^{-1}$ OVA (grade II, Sigma-Aldrich) as described previously [13]. As no OVA-specific immunoglobulin (Ig) $\mathrm{E}$ and $\mathrm{IgG}_{1}$ standards exist, values were expressed in units of optical density (OD).

\section{Statistical analysis}

All data are presented as mean \pm SEM. Differences among the treatment groups were assessed by one-way or two-way ANOVA. Significant ANOVAs were further analysed by Bonferroni post hoc test. Two-way ANOVA was used to analyse the dose-response curves. Otherwise one-way ANOVA was used in all other statistic analysis. ED50 was analysed as log-values to follow normal distribution. A p-value of $<0.05$ was considered significant. Statistical analysis and graphs were performed in Graph Pad Prism (version 5.0; GraphPad Software Inc., San Diego, CA, USA).

\section{RESULTS}

\section{Sensitisation}

Sensitisation was confirmed by increased levels of OVAspecific $\operatorname{IgE}(\mathrm{OD} 0.17 \pm 0.02 ; \mathrm{p}<0.01)$ and $\mathrm{IgG}_{1}(\mathrm{OD} 0.69 \pm 0.08$; $\mathrm{p}<0.001$ ) compared with naïve mice (OD $0.07 \pm 0.01$ and $0.05 \pm 0.00$, respectively).

\section{Intervention with COX inhibitors during both OVA and MCh challenge \\ AHR}

There were generally no differences in baseline $R \mathrm{~L}$ and $\mathrm{CL}$ between the different treatments. In OVA, sensitised and challenged mice both the airway resistance (RL,max $5.9 \pm 0.2 \mathrm{cmH}_{2} \mathrm{O} \cdot \mathrm{s}^{-1} \cdot \mathrm{mL}^{-1} ; \mathrm{p}<0.001$ ) and the sensitivity (calculated as ED50 $0.37 \pm 0.06 \mathrm{mg} \cdot \mathrm{kg}^{-1}$ body weight; $\mathrm{p}<0.001$ ) to tailvein injection of $\mathrm{MCh}$ was substantially increased compared with PBS-challenged controls $\left(4.1 \pm 0.2 \mathrm{cmH}_{2} \mathrm{O} \cdot \mathrm{s}^{-1} \cdot \mathrm{mL}^{-1}\right.$ and $0.75 \pm 0.09 \mathrm{mg} \cdot \mathrm{kg}^{-1}$ body weight, respectively; fig. 2a; table 1 ).

There were no changes in lung resistance or sensitivity in sensitised and PBS-challenged mice treated with either of the COX inhibitors compared with PBS controls alone $(\mathrm{p}>0.05$; fig. 2a).

Administration of the nonselective COX inhibitor diclofenac and the selective COX-1 inhibitor FR122047 during OVA challenge (fig. 1) produced a significantly enhanced airway resistance compared with OVA sensitisation and challenge controls $(p<0.001$; fig. $2 b)$. Despite the marked increase in amplitude after treatment with diclofenac and FR122047, there was however no further change in sensitivity ( $\mathrm{p}>0.05$; table 1$)$. In contrast, the selective COX-2 inhibitor lumiracoxib did not change either the airway resistance or sensitivity compared with OVA-challenge controls ( $p>0.05$; fig. $2 b$; table 1 ).

Lung compliance was measured to assess a second parameter of lung function. The sensitisation and challenge with OVA induced a decrease in $C_{L}(p<0.001$; fig. $2 c)$ compared with the control mice. In mice treated with diclofenac and FR122047, but not lumiracoxib, the change in $C_{L}$ was further decreased $(\mathrm{p}<0.05$; fig. $2 \mathrm{c})$, reflecting the altered $R \mathrm{~L}$ with these treatments (fig. 2b).

\section{Cellular response in BAL}

Compared with PBS controls, the total cell number and the number of eosinophils in BAL were markedly increased in OVA sensitised and challenged mice $(p<0.001)$ as well as macrophages, neutrophils and lymphocytes $(\mathrm{p}<0.01, \mathrm{p}<0.01$ and $\mathrm{p}<0.001$, respectively; fig. 3 ). In mice treated with diclofenac or lumiracoxib, the total cell response was reduced $(p<0.001)$ as well as the number of eosinophils $(p<0.01$ and $\mathrm{p}<0.001$, respectively; fig. 3). Treatment with FR122047 did not significantly alter the total cell response. In PBS-challenged control groups, diclofenac had no effect on total cell number or composition of the cells in the BAL fluid (fig. 3).

\section{Levels of prostanoids and CysLTs in BAL}

The levels of $\mathrm{PGD}_{2}(\mathrm{p}<0.001$; fig. $4 \mathrm{a}), \mathrm{PGE}_{2}$ ( $\mathrm{p}<0.001$; fig. $\left.4 \mathrm{~b}\right)$, $\mathrm{TXA}_{2}$ ( $\mathrm{p}<0.001$; fig. $4 \mathrm{c}$ ) and CysLTs ( $<<0.01$; fig. $\left.4 \mathrm{~d}\right)$ increased significantly in BAL above basal levels in OVA-challenged mice. For the prostanoids, the ratio of release was $\mathrm{PGE}_{2}$ $>>\mathrm{PGD}_{2}>\mathrm{TXA}_{2}$ (21.8, 5.3 and 1 , respectively).

Treatment with diclofenac or FR122047 significantly inhibited basal and OVA induced release of $\operatorname{PGD}_{2}(\mathrm{p}<0.001$; fig. 4a), $\mathrm{PGE}_{2} \quad(\mathrm{p}<0.001$; fig. $4 \mathrm{~b})$ and $\mathrm{TXA}_{2} \quad(\mathrm{p}<0.001$; fig. $4 \mathrm{c})$. Lumiracoxib attenuated the production of $\mathrm{TXA}_{2} \quad(\mathrm{p}<0.01$; 

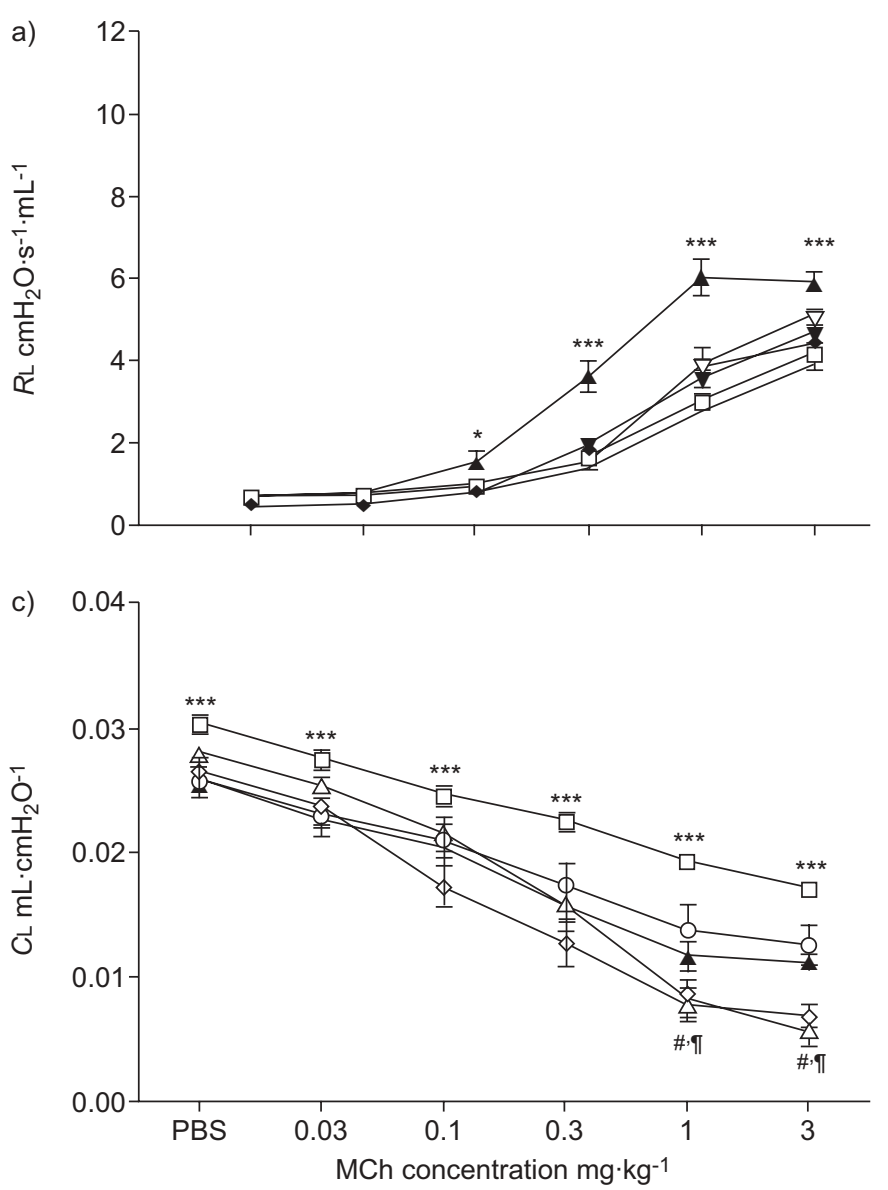

fig. 4c) and there was a tendency for $\mathrm{PGE}_{2}$ inhibition, but it was not able to cause the same degree of inhibition of the release of $\mathrm{PGD}_{2}$ ( $\mathrm{p}>0.05$; fig. $4 \mathrm{a}$ and $\mathrm{b}$ ). None of the three COX inhibitors had any effect on the CysLTs ( $p>0.05$; fig. $4 d$ ).

Levels of cytokines in BAL

OVA challenge increased the BAL levels of IL-4 (5.5-fold; $\mathrm{p}<0.01$; fig. 5a), IL-5 (10.3-fold; $\mathrm{p}<0.001$; fig. 5b) and IL-13 (5.2fold; $\mathrm{p}<0.01$; fig. $5 \mathrm{c}$ ). Treatment with COX inhibitors generally induced no change in the level of cytokines in BAL fluid compared with OVA controls (fig. 5), with the exception that mice treated with diclofenac had slightly reduced levels of IL-4 b)

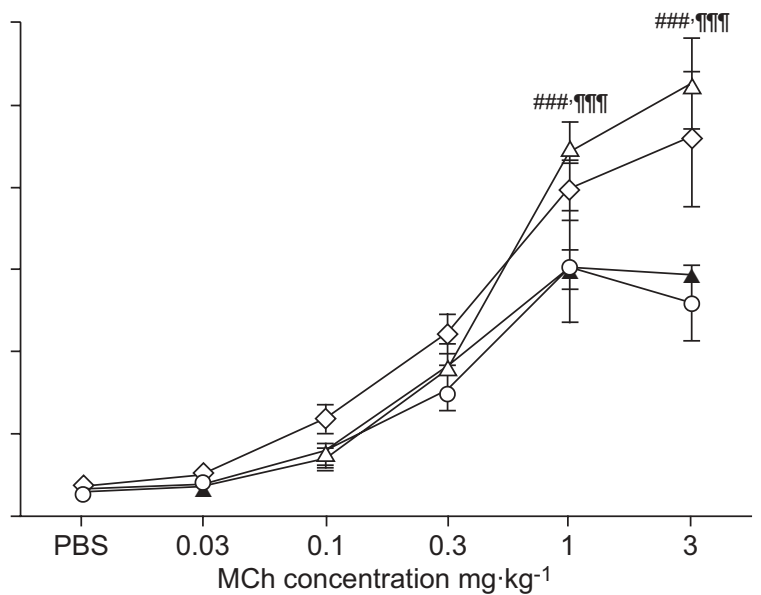

FIGURE 2. $\mathrm{a}$ and $\mathrm{b})$ Lung resistance $(R L)$ to methacholine $(\mathrm{MCh})$ after ovalbumin (OVA) sensitisation and OVA or PBS challenge (OVA is similar in a and b). c) Pulmonary compliance (CL) to MCh after OVA sensitisation and OVA or PBS challenge. Drug interventions were administrated both during the OVA challenge and prior to the MCh challenge. Data points are represented as mean \pm SEM. a) PBS $(\square)$ : $n=12$; PBS-diclofenac $(\bullet)$ : $n=6$; PBS-FR122047 $(\nabla)$ : $\mathrm{n}=6$; PBS-lumiracoxib $(\mathbf{\nabla})$ : n=6; OVA $(\mathbf{\Delta}): \mathrm{n}=12$. b) OVA: $\mathrm{n=12}$; OVAdiclofenac $(\triangle)$ : $n=7$; OVA-FR122047 $(\diamond)$ : $n=9$; OVA-lumiracoxib $(O)$ : $n=8 . c)$ PBS: $n=12$; OVA: $n=12$; OVA-diclofenac: $n=7$; OVA-FR122047: $n=9$; OVAlumiracoxib: $n=8 .{ }^{* * *}: p<0.001$ and $*: p<0.05$ OVA compared with PBS-

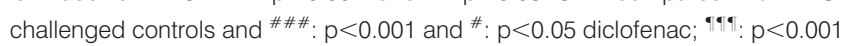
and ${ }^{\circ}: p<0.05$ FR122047 compared with OVA controls.

(four-fold; $\mathrm{p}<0.05$ ) compared with OVA (fig. 5a). In PBSchallenged control groups, diclofenac had no effect on the release of cytokines in the BAL fluid. There were no detectable levels of IL-10, TNF or IFN- $\gamma$ in any of the groups.

\section{Intervention with COX inhibitors during either OVA or MCh challenge}

Administration of diclofenac only during OVA challenge did not further increase the resistance to MCh compared with OVA controls (fig. 6a), but significantly reduced the cell response in BAL ( $<<0.01$; fig. 6b).

\section{TABLE 1 Measurement of airway function in anaesthetised mice following ovalbumin (OVA) or PBS challenge: the maximal reactivity and sensitivity to methacholine challenge}

Maximal reactivity $\mathrm{cmH}_{2} \mathrm{O} \cdot \mathrm{s}^{-1} \cdot \mathrm{mL}^{-1}$

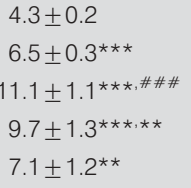

$4.3 \pm 0.2$

$11.1+1.1^{* * *}, \# \# *$

$7.1 \pm 1.2^{\star *}$
Sensitivity ED50 $\mathrm{mg} \cdot \mathrm{kg}^{-1}$ body weight

$0.75 \pm 0.09$
$0.37 \pm 0.06^{\star \star *}$
$0.53 \pm 0.09^{\star * *}$
$0.39 \pm 0.08^{\star \star *}$
$0.47 \pm 0.10^{\star \star *}$

Data are presented as mean \pm SEM. ED50: effective dose for half maximal response. ${ }^{\star \star \star}: \mathrm{p}<0.001$ compared with control; ${ }^{\# \# \#}: \mathrm{p}<0.001$ and ${ }^{\star \star}: \mathrm{p}<0.01$ compared with OVA controls. 

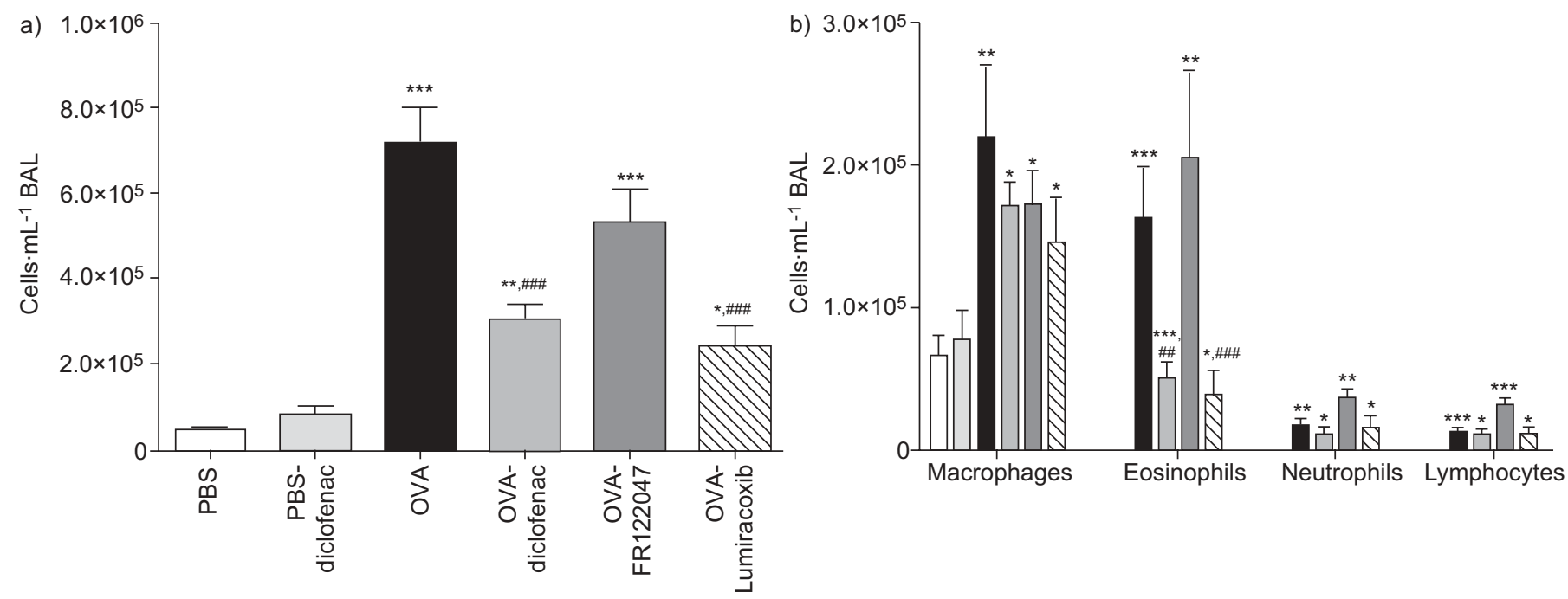

FIGURE 3. a) Total cell count in bronchoalveolar lavage (BAL) fluid in ovalbumin (OVA) sensitised and OVA or PBS-challenged mice. b) Cellular composition in BAL. Drug interventions were administrated both during the OVA challenge and prior to methacholine challenge. Data are represented as mean \pm SEM. a) PBS: $n=12$; PBSdiclofenac: $n=6$; OVA: $n=12$; OVA-diclofenac: $n=8$; OVA-FR122047: $n=12$; OVA-lumiracoxib: $n=12$. b) PBS: $n=12 ;$ PBS-diclofenac: $n=6$; OVA: $n=11 ;$ OVA-diclofenac: $\mathrm{n}=8$; OVA-FR122047: $\mathrm{n}=12$; OVA-lumiracoxib: $\mathrm{n}=10$. $\square$ : PBS; $\square:$ PBS diclofenac; $\mathbf{\square}:$ OVA; $\square:$ OVA-diclofenac; $\square:$ OVA-FR122047; $\mathbb{\mathbb { N }}$ : OVA-lumiracoxib. *: $\mathrm{p}<0.05$;

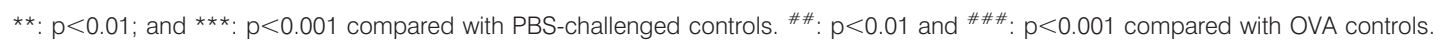

When diclofenac was administered only prior to $\mathrm{MCh}$ challenge, the resistance to $\mathrm{MCh}$ was enhanced $(\mathrm{p}<0.01$; fig. 6c), compared with OVA controls. In contrast to animals that received diclofenac during OVA challenge (figs $3 a$ and 6b) there was no reduction in cell response in BAL (fig. 6d).

\section{DISCUSSION}

The aim of the current study was to gain a more detailed understanding of the role of COX products in the eosinophilic airway reaction induced by OVA challenge in sensitised animals. It was discovered that there was a dissociation of the effects of COX inhibition during the OVA challenge on airway inflammation and AHR, suggesting that inflammatory cells in BAL do not change in parallel with AHR. Intervention with COX-inhibitors during the OVA challenge indicated that COX-1 activity predominantly generated prostanoids that are bronchoprotective and thus, serve to protect against further increases in AHR. In contrast, COX-2 activity was associated with infiltration of inflammatory cells in the lung, supporting a pro-inflammatory function of that pathway. Therefore, the findings also indicated distinct roles of prostanoids generated along the COX-1 and COX-2 pathways.

Further investigation of the time-point of action of COX inhibition, showed that the administration of diclofenac only during the OVA challenge reduced the cell response in BAL without any effect on the increased AHR to MCh induced by the allergen challenge (fig. $6 \mathrm{a}$ and b). In contrast, administration of diclofenac only prior to the MCh challenge enhanced allergen-induced AHR to MCh but did not affect cell response in BAL (fig. 6c and d). In mice sensitised but not challenged with OVA, COX inhibition did not affect RL or ED50 to MCh (fig. 2a). This finding supports that the effect of COX inhibition was not a consequence of changes in baseline airway physiology but due to interference with a functional change that was caused by the OVA challenge.
Furthermore, OVA challenge increased AHR to MCh both with increased reactivity and sensitivity. Inhibition with diclofenac and FR122047, caused a further increase of reactivity without a change in sensitivity to MCh, whereas the selective COX-2 inhibition by lumiracoxib did not change the AHR induced by OVA alone. These findings (table 1) suggest that the enhanced AHR is caused by COX-1 inhibition that it is due to an effect on smooth muscle hyperreactivity, whereas the increased AHR after OVA challenge compared with PBS controls includes additional changes that also affect the sensitivity to MCh [14]. There is indeed data from studies in asthmatics to support primary modulation of airway smooth muscle reactivity as a distinct effect in AHR, induced for example by drug treatments $[15,16]$.

Our findings, implicating that the COX-1 pathway is critical for determination of AHR in this model, are consistent with the decreased AHR to MCh in mice deficient of COX-2 and overexpressing human COX-1 [17]. Likewise, studies in mice deficient of either COX-1 or COX-2 genes showed that only the allergic $\mathrm{COX}-1^{-/-}$mice exhibited increased airway reactivity to MCh $[3,4]$. Thus, PGs generated by COX-1 activity have a bronchoprotective role.

Mice treated with diclofenac and lumiracoxib during OVA challenge had decreased eosinophilic inflammation in BAL, whereas FR122047 did not affect the cellular response. This indicates that COX-2 generates prostanoids that mediate the accumulation of cells in the airways. It has been reported that mice deficient in COX-2 and over-expressing human COX-1, or animals with COX-inhibition before sensitisation, showed a similar or increased inflammatory response similar to OVA controls $[1,2,17]$. In contrast, mice deficient in either COX-1 or COX-2 demonstrated an attenuated inflammation [4], again indicating a role for COX products to recruit inflammatory cells. Moreover, although a decrease of inflammation was seen 

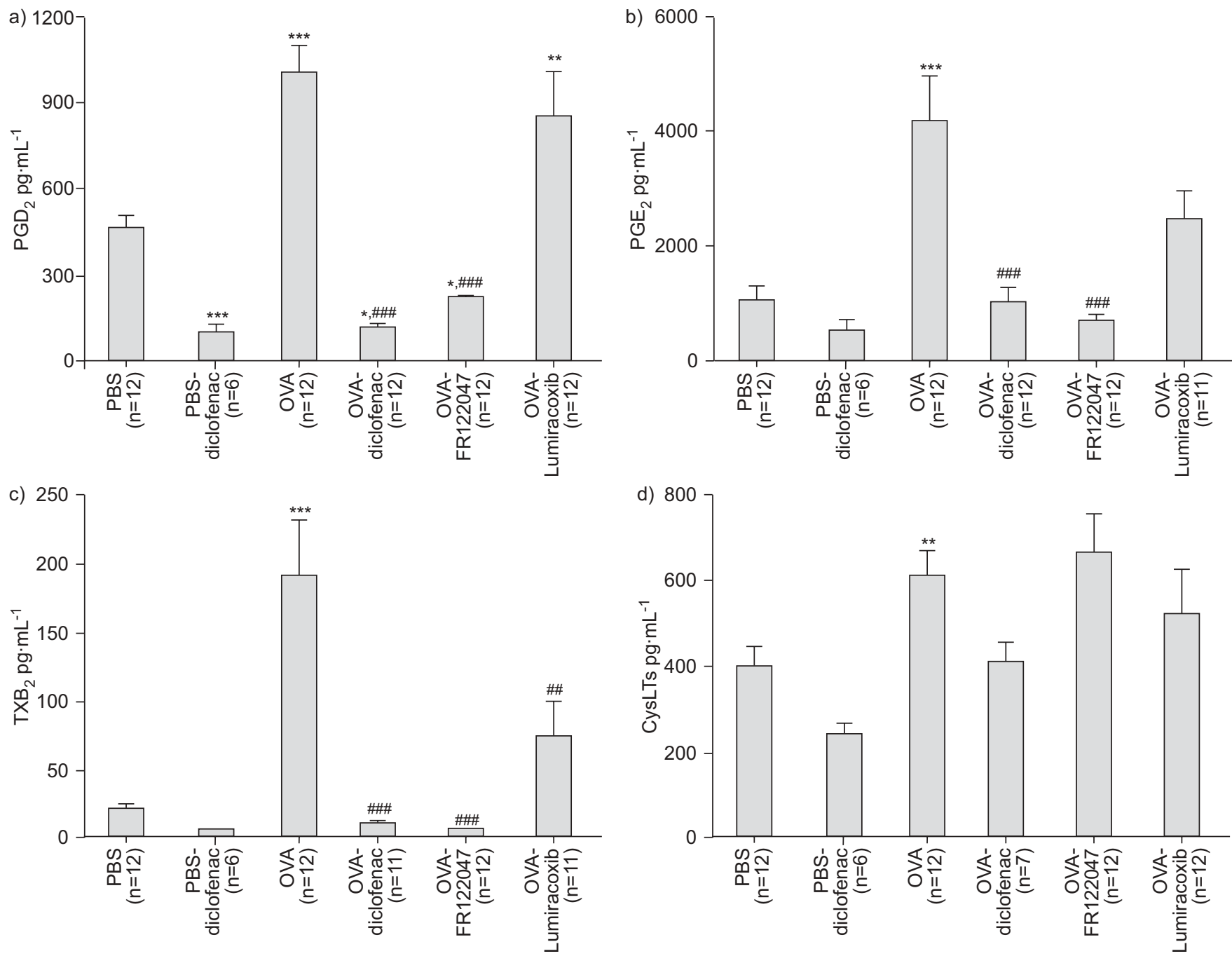

FIGURE 4. Release of mediators in bronchoalveolar lavage (BAL) fluid in ovalbumin (OVA) sensitised and OVA or PBS-challenged mice (mean \pm SEM). Concentration (pg.mL ${ }^{-1} \mathrm{BAL}$ ) of a) prostaglandin ( $\left.\mathrm{PG}\right) \mathrm{D}_{2}$, b) $P G E_{2}, \mathrm{c}$ ) thromboxane (TXA) $\mathrm{B}_{2}$ and d) cysteinyl leukotrienes (CysLT). Drug interventions were administrated both during the OVA challenge and prior to methacholine challenge. ${ }^{*}: p<0.05$; ${ }^{* *}: p<0.01$; and ${ }^{* * *}: p<0.001$ compared with PBS-challenged controls. ${ }^{\# \#: ~} p<0.01$ and ${ }^{\# \# \#: ~} p<0.001$ compared with OVA controls.

in our experiments after COX-2 inhibition, the allergeninduced AHR was obtained to the same degree as in animals not given the inhibitor. This lends support to the concept of separate effects of prostanoids on airway inflammation and AHR.

Whereas the study established the different effects of isoenzyme selective COX inhibitors on AHR and inflammation, it does not define the particular PG that mediated the effects of the inhibition. However, both $\mathrm{PGD}_{2}$ and $\mathrm{PGE}_{2}$ induce strong and potent relaxations of mice airway smooth muscle through activation of $\mathrm{DP}_{1}$ and $\mathrm{EP}_{2}$ receptors, respectively, [18-20], and COX-1 inhibition caused an attenuation of $\mathrm{PGD}_{2}$ and $\mathrm{PGE}_{2}$ in BAL. Therefore, it is likely that the enhancing effects of COX-1 inhibition on the increased AHR after OVA challenge may be explained in terms of removal of $\mathrm{PGE}_{2}$ and $\mathrm{PGD}_{2}$. Consistent with our study, PEEBLES and colleagues $[1,2]$ also found that COX inhibition caused a reduction of $\mathrm{PGE}_{2}$ levels together with an enhanced AHR. However, in their study, not only
COX-1 but also COX-2 inhibition decreased $\mathrm{PGE}_{2}$, which may seem to be at variance with our results $[1,2]$. As they used a different COX-2 inhibitor [21] and also administered COXinhibitors prior to sensitisation and continuously during the whole study $[1,2]$, the data are not directly comparable and further studies are required to resolve this issue.

In our study, the selective COX-2 inhibition by lumiracoxib was not able to cause the same degree of inhibition of $\mathrm{PGE}_{2}$ and $\mathrm{PGD}_{2}$ as COX-1 inhibition in BAL and it did not affect the OVA-induced AHR, further supporting the interpretation that these two PGs are likely to serve a bronchoprotective function. In line with our findings in this murine model, protective activity of $\mathrm{PGE}_{2}$ is also observed in asthmatics [22]. Inhalation of $\mathrm{PGE}_{2}$ prevents allergen-induced early and late airway responses after allergen challenge [23-25]. The effect of $\mathrm{PGE}_{2}$ on the airway responses to allergens may be explained both in terms of relaxation of the smooth muscles and by inhibition of the release of mast-cell mediators [26]. However, as COX 

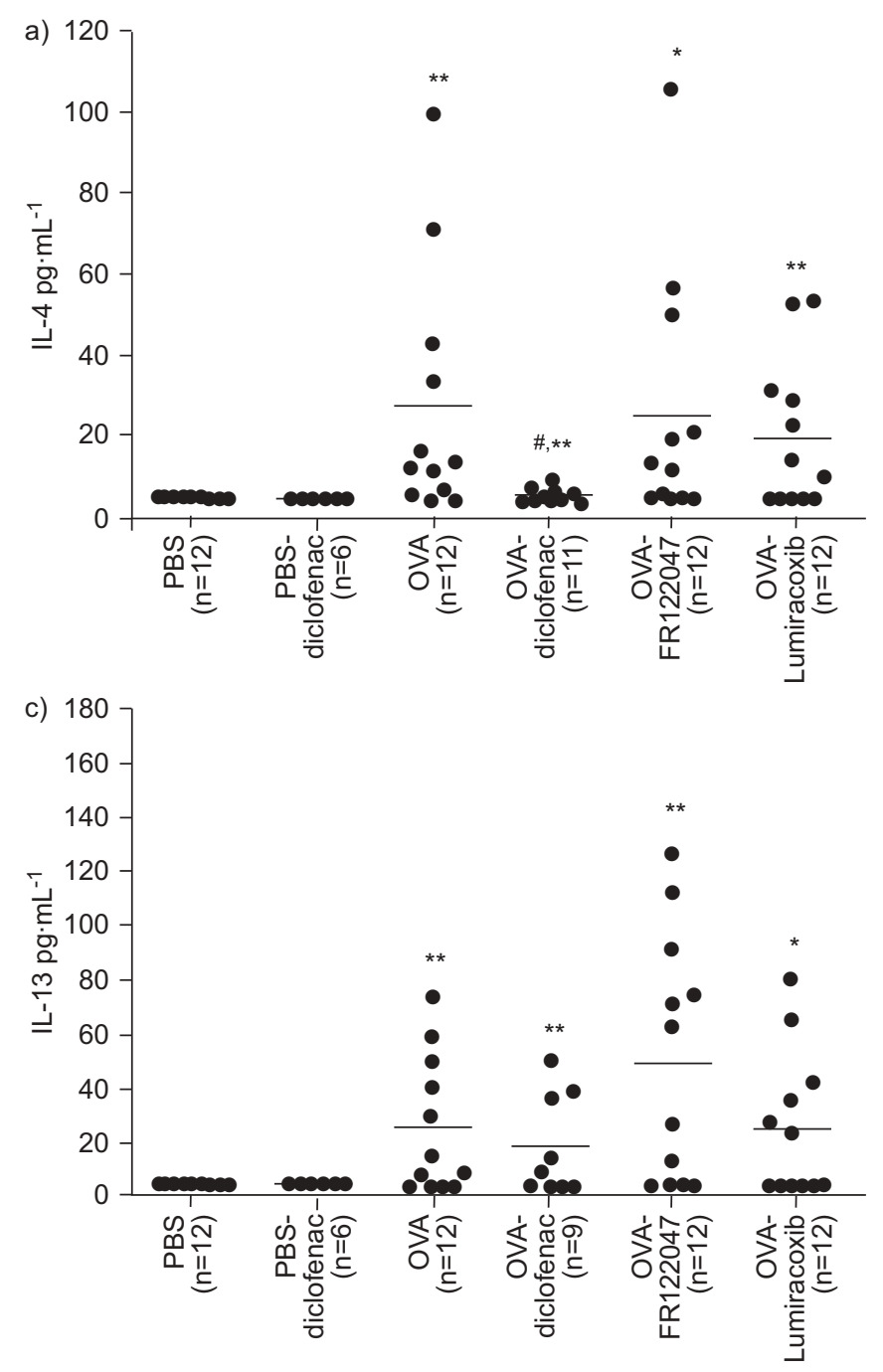

inhibition did not affect the allergen-evoked release of CysLT or cytokines in our study, it is concluded that smooth muscle relaxation was the predominant mechanism in this particular model.

It is acknowledged that our data do not define which PG mediated the COX-2 dependent effects on cellular inflammation. Local synergy in the tissue between vascular effects of $\mathrm{PGE}_{2}$ and chemotactic mediators [27, 28], or chemoattractant receptor-homologous molecule expressed on T-helper type (Th) 2 cell-mediated effects of $\mathrm{PGD}_{2}[22,29]$ are two possible explanations but further studies are required to resolve the mechanism.

Confirming previous reports [30, 31], the major Th2 cytokines, IL-4, IL-5 and IL-13, were increased in BAL after OVA sensitisation. Previous studies have linked the development of OVA-induced AHR in particular to increased IL-13 levels observed after inhibition of either COX-1 or COX-2 [1, 2]. This particular increase of IL-13 was documented 4 days before assessment of AHR. However, consistent with our findings, the level of IL-13 was no different from animals challenged with OVA in the absence of COX inhibition at the time of AHR measurements $[1,2]$. It is possible that changes in cytokine

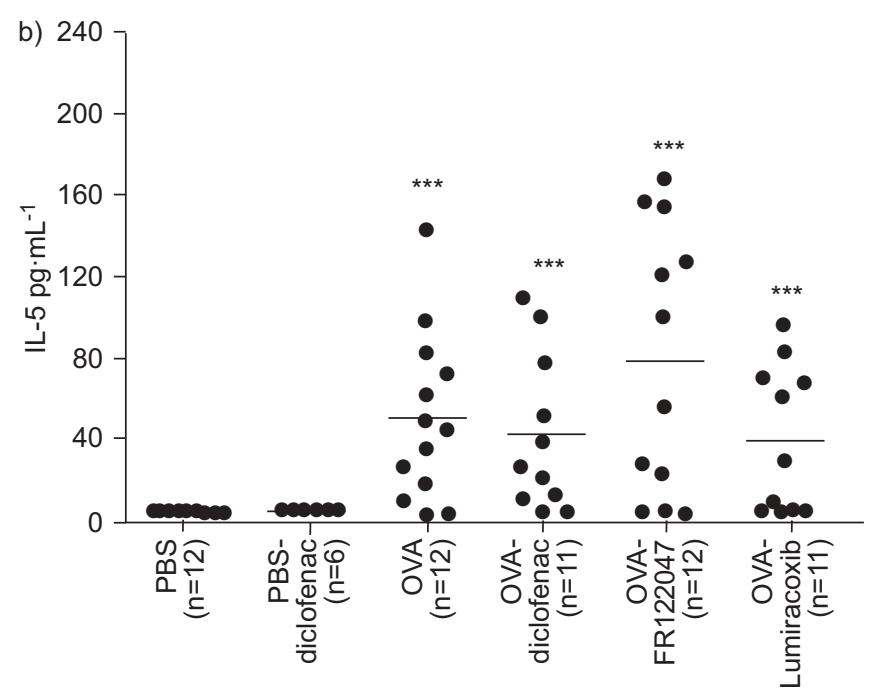

FIGURE 5. Cytokine release in bronchoalveolar lavage (BAL) fluid in ovalbumin (OVA) sensitised and OVA or PBS-challenged mice. Levels of a) interleukin (IL)-4, b) IL-5 and c) IL-13. Drug interventions were administrated both during the OVAchallenge and prior to methacholine challenge. Results are expressed as points and mean. Each point represents results from one animal. *: $p<0.05 ; * *$ : $p<0.01$; and $* * *: p<0.001$ compared with PBS-challenged controls and ${ }^{*}: p<0.05$ compared with OVA controls.

levels during OVA challenge in the presence of COX inhibition may have contributed to our results but we did not measure the cytokines during the OVA challenge period. Conversely, the observed changes in $\mathrm{PGE}_{2}$ and $\mathrm{PGD}_{2}$ levels in $\mathrm{BAL}$, together with the finding that AHR also increased when the COX inhibitor was given only during the day when AHR was assessed, suggests that modulation of OVA-induced increase of $\mathrm{PGE}_{2}$ and $\mathrm{PGD}_{2}$ in airway smooth muscle is sufficient to explain the amplificating effect of COX inhibition on AHR.

In conclusion, mice treated with a selective COX-1 inhibitor had enhanced AHR but no change in the accumulation of inflammatory cells in the lung, whereas mice treated with a selective COX-2 inhibitor displayed a decrease of cells in the BAL but no change of AHR. The implications of separate functions for COX-1 and COX-2 products gained further support as treatment with the nonselective COX inhibitor diclofenac combined the effects seen with the two selective COX inhibitors. The combined effects of the unselective COX inhibitor diclofenac on AHR and BAL cells also supports the fact that doses of FR122047 and lumiracoxib used in this study were effective and selective. Taken together, the present study indicates that AHR and the airway inflammatory response are 

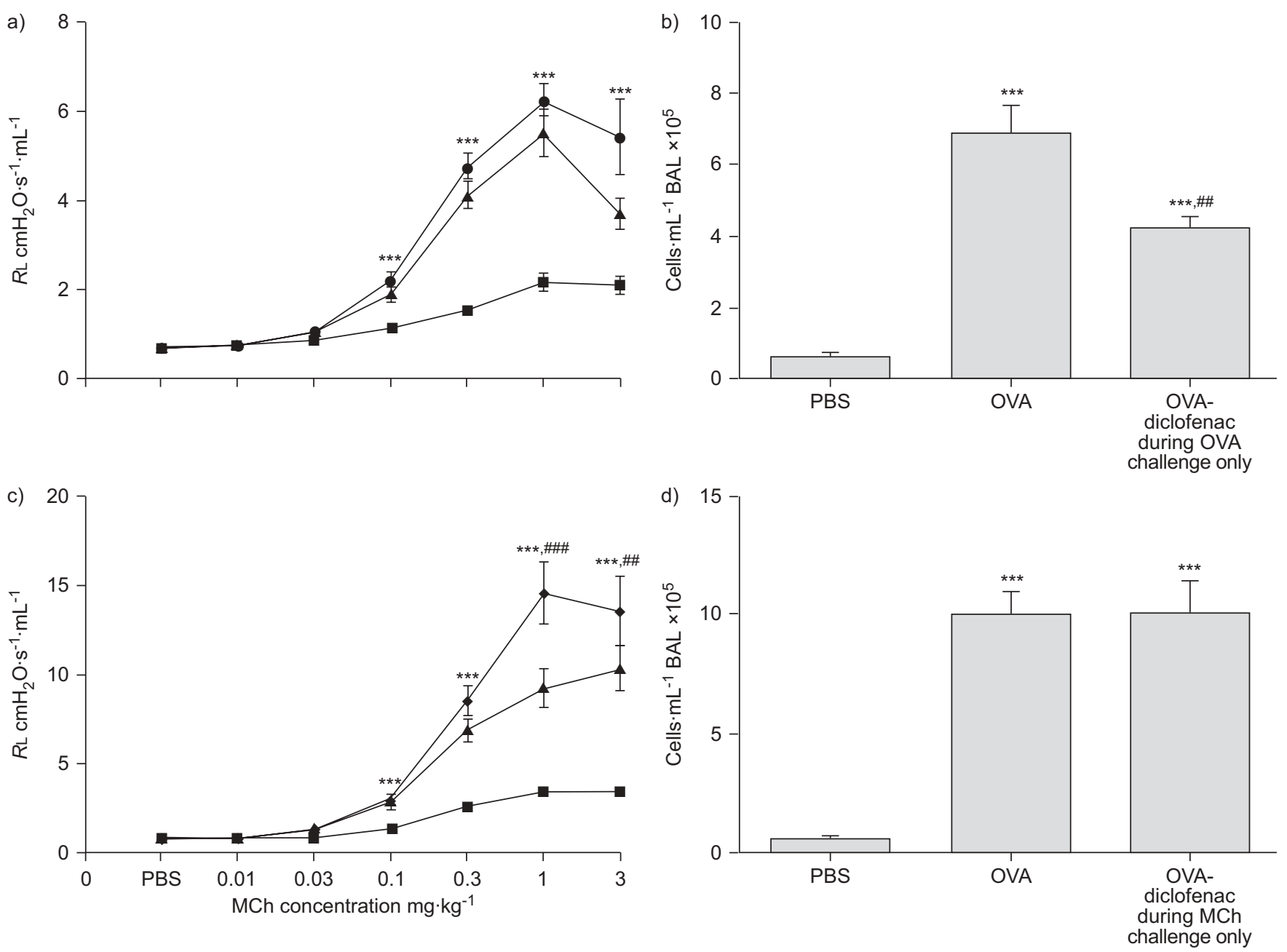

FIGURE 6. Ovalbumin (OVA) sensitisation and challenge in mice treated with diclofenac a and b) only during OVA challenge or $\mathrm{c}$ and d) only during methacholine (MCh) challenge. $a$ and c) Lung resistance $(R L)$ to $M C h$ and $b$ and d) total cell count in bronchoalveolar lavage (BAL) fluid. Data points are represented as mean \pm SEM. a) PBS (

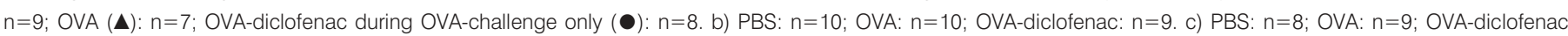
during MCh-challenge only $(\bullet)$ : $n=9$. d) PBS: $n=10$; OVA: $n=10$; OVA-diclofenac during MCh-challenge only: $n=10$. **: $p<0.001$ compared with PBS-challenged controls. $\#$ \# $p<0.05$; and ${ }^{\# \# \#: ~} p<0.001$ diclofenac compared with OVA controls.

distinct, and at least in part, uncoupled events. Furthermore, there is also a difference in time for the development of the two separate reactions during allergen challenge. This is, in fact, in line with recent observations in subjects with asthma where BAL inflammation is not a predictive surrogate marker of AHR [32].

\section{SUPPORT STATEMENT}

The current study was supported by the Swedish Heart Lung Foundation, the Swedish Research Council, the Stockholm Country Council Research Funds (ALF) and Karolinska Institutet (all Stockholm, Sweden).

\section{STATEMENT OF INTEREST}

A statement of interest for this study can be found at www.erj. ersjournals.com $/ \mathrm{misc} /$ statements.dtl

\section{ACKNOWLEDGEMENTS}

The authors would like to thank A. Hesselgren (Dept of Medical Biochemistry and Biophysics) for animal care and her assistance, I. Delin (The National Institute of Environmental Medicine, Division of
Physiology; both Karolinska Institutet, Stockholm, Sweden) for EIA consulting and L. Gold (Scireq, Montreal, QC, Canada) for technical FlexiVent ${ }_{\circledast}$ support.

\section{REFERENCES}

1 Peebles RS Jr, Hashimoto K, Morrow JD, et al. Selective cyclooxygenase- 1 and -2 inhibitors each increase allergic inflammation and airway hyperresponsiveness in mice. Am J Respir Crit Care Med 2002; 165: 1154-1160.

2 Peebles RS Jr, Dworski R, Collins RD, et al. Cyclooxygenase inhibition increases interleukin 5 and interleukin 13 production and airway hyperresponsiveness in allergic mice. Am J Respir Crit Care Med 2000; 162: 676-681.

3 Carey MA, Germolec DR, Bradbury JA, et al. Accentuated T-helper type 2 airway response after allergen challenge in cyclooxygenase- $1^{-/-}$but not cyclooxygenase- $2^{-/-}$mice. Am J Respir Crit Care Med 2003; 167: 1509-1515.

4 Gavett SH, Madison SL, Chulada PC, et al. Allergic lung responses are increased in prostaglandin $\mathrm{H}$ synthase-deficient mice. J Clin Invest 1999; 104: 721-732. 
5 FitzGerald GA. COX-2 and beyond: approaches to prostaglandin inhibition in human disease. Nat Rev Drug Discov 2003; 2: 879-890.

6 Epstein MM. Do mouse models of allergic asthma mimic clinical disease? Int Arch Allergy Immunol 2004; 133: 84-100.

7 Mitchell JA, Akarasereenont $\mathrm{P}$, Thiemermann C, et al. Selectivity of nonsteroidal antiinflammatory drugs as inhibitors of constitutive and inducible cyclooxygenase. Proc Natl Acad Sci USA 1993; 90: 11693-11697.

8 Esser R, Berry C, Du Z, et al. Preclinical pharmacology of lumiracoxib: a novel selective inhibitor of cyclooxygenase-2. $\mathrm{Br} \mathrm{J}$ Pharmacol 2005; 144: 538-550.

9 Ochi T, Motoyama Y, Goto T. The analgesic effect profile of FR122047, a selective cyclooxygenase- 1 inhibitor, in chemical nociceptive models. Eur J Pharmacol 2000; 391: 49-54.

10 Barnas GM, Ho G, Green MD, et al. Effects of analysis method and forcing waveform on measurement of respiratory mechanics. Respir Physiol 1992; 89: 273-285.

11 Tomioka S, Bates JH, Irvin CG. Airway and tissue mechanics in a murine model of asthma: alveolar capsule $v$ s forced oscillations. J Appl Physiol 2002; 93: 263-270.

12 Hjoberg J, Shore S, Kobzik L, et al. Expression of nitric oxide synthase- 2 in the lungs decreases airway resistance and responsiveness. J Appl Physiol 2004; 97: 249-259.

13 Neimert-Andersson T, Thunberg S, Swedin L, et al. Carbohydratebased particles reduce allergic inflammation in a mouse model for cat allergy. Allergy 2008; 63: 518-526.

14 Grootendorst DC, Rabe KF. Mechanisms of bronchial hyperreactivity in asthma and chronic obstructive pulmonary disease. Proc Am Thorac Soc 2004; 1: 77-87.

15 Hakonarson H, Halapi E, Whelan R, et al. Association between IL$1 \beta / \mathrm{TNF} \alpha$-induced glucocorticoid-sensitive changes in multiple gene expression and altered responsiveness in airway smooth muscle. Am J Respir Cell Mol Biol 2001; 25: 761-771.

16 Slats AM, Janssen K, van Schadewijk A, et al. Expression of smooth muscle and extracellular matrix proteins in relation to airway function in asthma. J Allergy Clin Immunol 2008; 121: 1196-1202.

17 Card JW, Carey MA, Bradbury JA, et al. Cyclooxygenase-1 overexpression decreases basal airway responsiveness but not allergic inflammation. J Immunol 2006; 177: 4785-4793.

18 Matsuoka T, Hirata M, Tanaka $H$, et al. Prostaglandin $D_{2}$ as a mediator of allergic asthma. Science 2000; 287: 2013-2017.

19 Richter M, Sirois P. Effects of eicosanoids, neuromediators and bioactive peptides on murine airways. Eur J Pharmacol 2000; 389: 225-234.
20 Tilley SL, Hartney JM, Erikson CJ, et al. Receptors and pathways mediating the effects of prostaglandin $\mathrm{E}_{2}$ on airway tone. Am J Physiol Lung Cell Mol Physiol 2003; 284: L599-L606.

21 Penning TD, Talley JJ, Bertenshaw SR, et al. Synthesis and biological evaluation of the 1,5-diarylpyrazole class of cyclooxygenase-2 inhibitors: identification of 4-[5-(4-methylphenyl)-3(trifluoromethyl)-1H-pyrazol-1-yl]benze nesulfonamide (SC-58635, celecoxib). J Med Chem 1997; 40: 1347-1365.

22 Gyles SL, Xue L, Townsend ER, et al. A dominant role for chemoattractant receptor-homologous molecule expressed on $\mathrm{T}$ helper type 2 (Th2) cells (CRTH2) in mediating chemotaxis of CRTH2+ CD4+ Th2 lymphocytes in response to mast cell supernatants. Immunology 2006; 119: 362-368.

23 Kunikata T, Yamane H, Segi E, et al. Suppression of allergic inflammation by the prostaglandin $\mathrm{E}$ receptor subtype $\mathrm{EP}_{3}$. Nat Immunol 2005; 6: 524-531.

24 Gauvreau GM, Watson RM, O'Byrne PM. Protective effects of inhaled $\mathrm{PGE}_{2}$ on allergen-induced airway responses and airway inflammation. Am J Respir Crit Care Med 1999; 159: 31-36.

25 Pavord ID, Wong CS, Williams J, et al. Effect of inhaled prostaglandin $\mathrm{E}_{2}$ on allergen-induced asthma. Am Rev Respir Dis 1993; 148: 87-90.

26 Hartert TV, Dworski RT, Mellen BG, et al. Prostaglandin $\mathrm{E}_{2}$ decreases allergen-stimulated release of prostaglandin $D_{2}$ in airways of subjects with asthma. Am J Respir Crit Care Med 2000; 162: 637-640.

27 Wedmore CV, Williams TJ. Control of vascular permeability by polymorphonuclear leukocytes in inflammation. Nature 1981; 289: 646-650.

28 Williams TJ. Interactions between prostaglandins, leukotrienes and other mediators of inflammation. Br Med Bull 1983; 39: 239-242.

29 Pettipher R, Hansel TT, Armer R. Antagonism of the prostaglandin $\mathrm{D}_{2}$ receptors DP1 and CRTH2 as an approach to treat allergic diseases. Nat Rev Drug Discov 2007; 6: 313-325.

30 Tomkinson A, Duez C, Cieslewicz G, et al. A murine IL-4 receptor antagonist that inhibits IL-4- and IL-13-induced responses prevents antigen-induced airway eosinophilia and airway hyperresponsiveness. J Immunol 2001; 166: 5792-5800.

31 Eum SY, Maghni K, Hamid Q, et al. Inhibition of allergic airways inflammation and airway hyperresponsiveness in mice by dexamethasone: role of eosinophils, IL-5, eotaxin, and IL-13. J Allergy Clin Immunol 2003; 111: 1049-1061.

32 Wardlaw AJ, Brightling CE, Green R, et al. New insights into the relationship between airway inflammation and asthma. Clin Sci (Lond) 2002; 103: 201-211. 